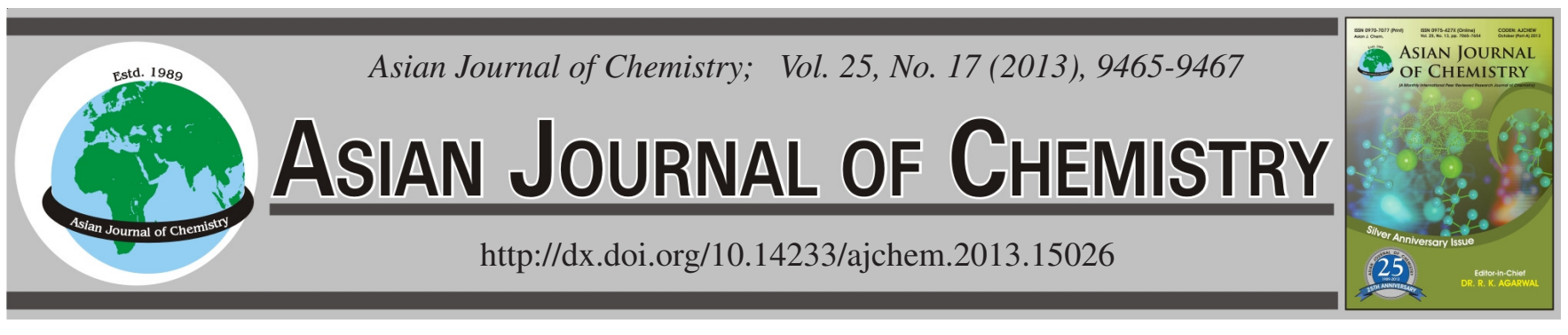

\title{
Decomposition of Oil Shale by Electron-Beam Irradiation at Vacuum Condition
}

\author{
W.J. ZHANG* , Y.H. LiU, D. WANG and X.X. XIN
}

School of Material and Metallurgy, Northeastern University, Shenyang, Liaoning 110004, P.R. China

*Corresponding author: E-mail: 6333787@qq.com

(Received: 26 December 2012;

Accepted: 1 October 2013)

AJC-14206

The electron-beam irradiation was used to investigate the fuel production generated from Fushun oil shale at vacuum condition. The
kerogen decomposition mechanism was demonstrated and the influence of reaction conditions on the produced gas was discussed.
Reaction results show that the gas yield increases along with the increasing of the electron-beam irradiation time. The maximum gas yield
is $7.18 \%$. Moreover, the gas yield is also proportional with the accelerating voltage. However, the pulse current has no obvious influence
on the gas yield. The electron-beam irradiation in vacuum limits the secondary decomposition reaction, which provides high yield of
hydrocarbon gas and depresses the formation of $\mathrm{H}_{2} \mathrm{O}$ and $\mathrm{H}_{2}$.

Key Words: Decomposition, Oil shale, Electron-beam, Irradiation.

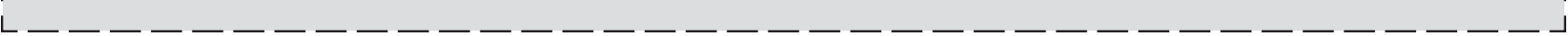

\section{INTRODUCTION}

With the depleting of the petroleum reserves, the utility of alternative energy sources is on the schedule. At present, oil shale is one of the most potential energy sources in the world and owns large deposits in almost all the continents. The energy capacity of the oil shale is 2.5 times than that of coal and 30 times than that of petroleum ${ }^{1}$. China possesses a very large oil shale resource in its 31.3 billion ton of characterized reserves in nine areas ${ }^{2}$. One of the largest deposits is Fushun oil shale with 4.13 billion ton estimated reserve located in Liaoning province ${ }^{3}$.

It is well known that the conventional pyrolysis is the common method to obtain shale oil from oil shale. Lots of works have been done on the characterization of oil shale pyrolysis to get shale oil ${ }^{4,5}$. However, such method has some disadvantages, i.e., low carbon conversion efficiency, low oil and gas yield. Consequently, the improvement of the method for more valuable transformations of oil shale becomes vital.

The effects of ionizing radiation on polymer materials have an extreme importance due to its initiation in chemical and physical changes. Ionizing radiation is a unique and powerful means of modifying polymer materials, specifically when the changes occur in solid-state, compared to chemical or thermal reactions, which should be carried out in hot or melting state ${ }^{6}$. The destruction and degradation of polymer can be initiated by ionizing radiation ${ }^{7}$. Ponomarev ${ }^{8}$ has found that the electron-beam distillation can transform plant materials to organic liquid fuel more productively than conventional dry distillation (pyrolysis). The yield of an organic condensate from cellulose wood and straw was $\geq 50 \mathrm{wt} \%$.

In this study, a series of oil shale specimens were irradiated by electron-beam. The residue of the oil shale was characterized by FT-IR and carbon hydrogen analyzer to identify the products and the yield of the formed gas.

\section{EXPERIMENTAL}

Oil shale samples preparation: The investigations were performed with oil shale sample obtained from Fushun oil shale deposits China. Kerogen was isolated wih chemical method $^{9}$ and the type of kerogen was found to be type II using FT-IR analysis technique in our previous study ${ }^{9}$. The results of Fisher Assay of the oil shale and elemental analysis of kerogen are given in Tables 1 and 2 .

\begin{tabular}{cccccc}
\multicolumn{7}{c}{ TABLE-1 } \\
\hline FiSHER ASSAY OF OIL SHALE (wt \%) \\
\hline Analysis & Shale oil & Gas & Decomposition water & Residue \\
\hline Content & 7.13 & 3.40 & \multicolumn{3}{c}{3.06} \\
\hline \multicolumn{5}{c}{ TABLE-2 } \\
\hline \multicolumn{7}{c}{ ELEMENTAL ANALYSIS OF KEROGEN (wt \%) } \\
\hline Elemental & $\mathrm{C}$ & $\mathrm{H}$ & $\mathrm{N}$ & $\mathrm{S}$ & $\mathrm{O}$ \\
\hline Content & 78.5 & 9.62 & 2.06 & 1.88 & 7.94 \\
\hline
\end{tabular}

The oil shale was ground, dried and sieved to give particles size of less than 200 meshes. The oil shale powders were molded into sheets with diameter of $3 \mathrm{~cm}$ and $1 \mathrm{~mm}$ thickness under $250 \mathrm{MPa}$ at room temperature. 
Electron-beam irradiation treatment: The electron-beam treatment was carried out by electron accelerator SOLO from Russia. The instrument parameters are listed in Table- 3 . The reactor pressure varied between $2.2-4.3 \times 10^{-2} \mathrm{~Pa}$. The current density and accelerate voltage were set to $2 \mathrm{kV}, 5 \mathrm{kV}, 10 \mathrm{kV}$, $13 \mathrm{kV}, 15 \mathrm{kV}, 200 \mathrm{~A}, 150 \mathrm{~A}, 100 \mathrm{~A}, 80 \mathrm{~A}$, respectively. The number of electron-beam irradiation was set to $20,30,40,50$, 60 times, respectively.

\begin{tabular}{lc}
\multicolumn{2}{c}{ TABLE-3 } \\
\multicolumn{2}{c}{ SPECIFICATIONS OF THE ELECTRON-BEAM } \\
ACCELERATOR AND IRRADIATION CONDITIONS \\
\hline \multicolumn{1}{c}{ Item } & Parameter \\
\hline Beam energy $(\mathrm{keV})$ & 30 \\
Accelerating voltage $(\mathrm{kV})$ & $2-15$ \\
Pulse current $(\mathrm{A})$ & $80-200$ \\
Pulse width $(\mu \mathrm{s})$ & 30 \\
Atmosphere & Air \\
Temperature $\left({ }^{\circ} \mathrm{C}\right)$ & 24 \\
\hline
\end{tabular}

Analysis methods: The residue is produced by decompositing the oil shale at vacuum condition. The gas yield is calculated as eqn. 1:

$$
\mathrm{Y}=\left[\frac{\left(\mathrm{W}_{0}-\mathrm{W}_{1}\right)}{\mathrm{W}_{0}}\right] \times 100
$$

where, $\mathrm{W}_{0}$ is the mass of the oil shale; $\mathrm{W}_{1}$ is the mass of the residues. The maximum pressure was recorded by electronbeam system equipped with a vacuum gauge. It must be noted that as the irradiation experiment is carried out under vacuum condition, the collection of the gas products is impossible. Consequently, in this study, the residues are analyzed to give some insight into the gaseous oil products. The content of carbon and hydrogen in the residue products were performed with a $\mathrm{CH} 400$ carbon hydrogen analyzer. The hydrogen and carbon elements in the specimens are combusted under oxygen stream at high temperature. The generated $\mathrm{CO}_{2}$ is then absorbed by absorbent. The content of the carbon is consequently calculated according to the weight gain of the absorbent. Meanwhile, the content of the hydrogen is shown on the carbon hydrogen analyzer directly. The carbon content of the gas products can be obtained by eliminating the carbon content of the solid residue from that of the oil shale. FT-IR of the pure oil shale and the solid residue products were obtained by Nicolet 380 apparatus.

\section{RESULTS AND DISCUSSION}

The influence of the electron-beam irradiation time on the gas yield are shown in Fig. 1. The accelerating voltage and pulse are $2 \mathrm{kV}, 5 \mathrm{kV}, 10 \mathrm{kV}, 13 \mathrm{kV}, 15 \mathrm{kV}, 200 \mathrm{~A}, 150 \mathrm{~A}$, $100 \mathrm{~A}, 80 \mathrm{~A}$, respectively. Fig. 1 showed that the gas yield increases along with the increasing of the electron-beam irradiation number when the experiment condition is the same, which can be reinforced by the change of the pressure in the processe (Fig. 2). The gas yield is $7.18 \%$, when the accelerating voltage and pulse current are $15 \mathrm{kV}$ and $200 \mathrm{~A}$.

Table-4 shows the effect of the accelerating voltage and pulse current on the gas yield. The results show that the gas yield depends on the accelerating voltage. The gas yield

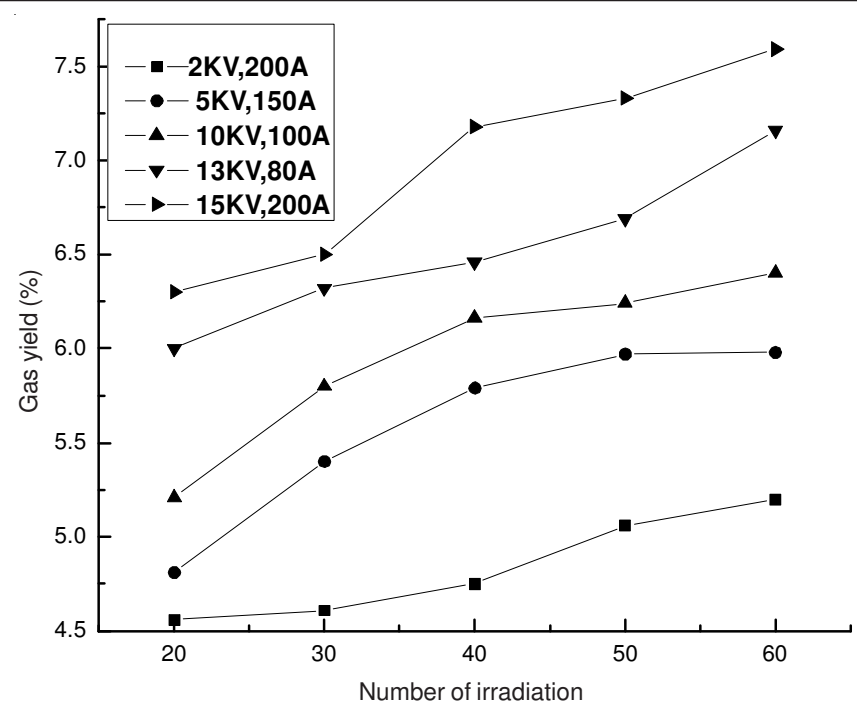

Fig. 1. Effect of the number of irradiation on the gas yield

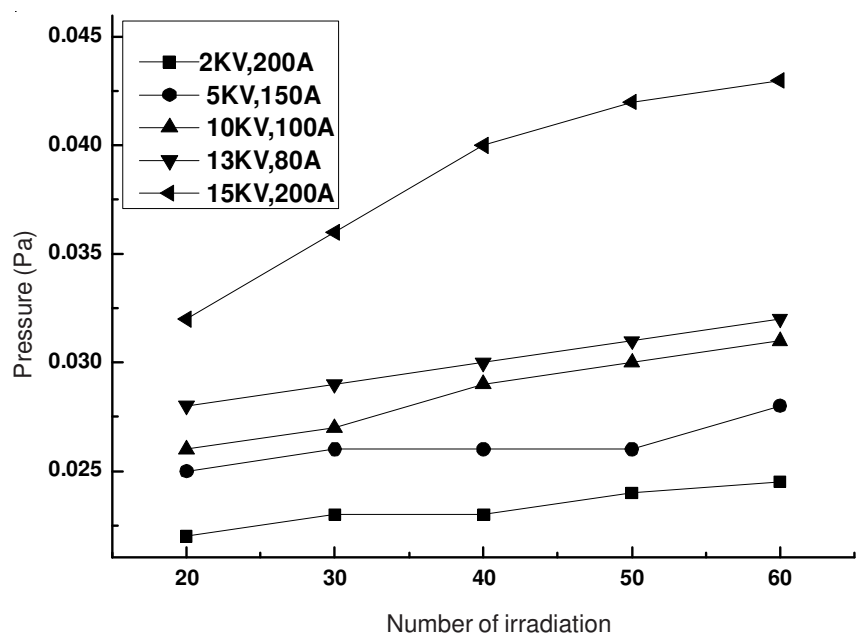

Fig. 2. Effect of the number of irradiation on the pressure

increases along with the increasing of the accelerating voltage. However, the pulse current has no obvious influence on the gas yield.

\begin{tabular}{ccccc}
\multicolumn{5}{c}{ TABLE-4 } \\
GAS YIELD AT DIFFERENT ACCELERATING \\
VOLTAGE AND PULSE CURRENT \\
\hline \multirow{2}{*}{ Sample } & $\begin{array}{c}\text { Accelerating } \\
\text { voltage }(\mathrm{kV})\end{array}$ & Pulse & Number of & Gas yield \\
& 2 & 150 & 40 & 6.29 \\
\hline 1 & 10 & 150 & 40 & 6.37 \\
2 & 15 & 150 & 40 & 7.06 \\
3 & 15 & 200 & 40 & 7.18 \\
4 & & & & irradiation \\
\hline
\end{tabular}

As has been mentioned, the instrument is working under vacuum condition. Consequently, it is impossible to collect the produced gas. In this sduy, the residues are analyzed to provide comparable information. Fig. 3 shows relative content of the carbon and the hydrogen under the condition of $15 \mathrm{kV}$ and $150 \mathrm{~A}$. The carbon and the hydrogen content of the products increased with increasing of the electron-beam irradiation number. The carbon and the hydrogen content of the solid residues are 2.68 and $0.21 \%$ after 60 number irradiation while those of the pure oil shale are 13.44 and $1.68 \%$, respectively. 


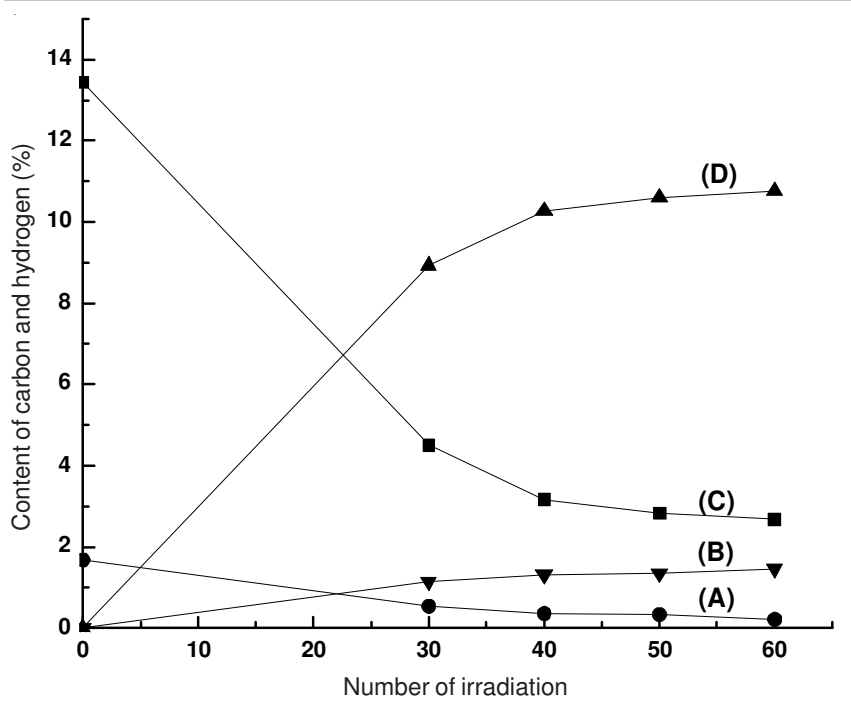

Fig. 3. Effect of the number of irradiation on the content of carbon and hydrogen; (A) the hydrogen content of the solid residue products, (B) the hydrogen content of the gas products, (C) the carbon content of the solid residue products, (D) the carbon content of the gas products

Chemical changes induced for oil shale specimens after treatment by electron-beam irradiation were monitored by FTIR spectroscopy (Fig. 4). Fig. 4 shows that all data (excepting the one for pristine residue product) have shifted upwards along the vertical axis by $5 \%$ relative to the previous data set. The experimental data was not shifted along the horizontal axis. Fig. 4 shows that there is no new band formed with the increasing of the irradiation number. The peak at 3700-3100 $\mathrm{cm}^{-1}$ corresponds the hydroxy group $(-\mathrm{OH})$. The aliphatic hydrocarbon stretching band is observed at 3000-2800 $\mathrm{cm}^{-1}$. The peak near $1650 \mathrm{~cm}^{-1}$ is associated with contribution of the aromatic and olefinic carbon double bonds. While the peak near $1100 \mathrm{~cm}^{-1}$ is related to the $\mathrm{Si}-\mathrm{O}$ group. The peak corresponds to the aliphatic hydrocarbon stretching band changes significantly in intensity among the residue products. The intensity of the aliphatic hydrocarbon peak decreases with the increasing of the irradiation number. This difference is attributed to the formation of the hydrocarbon gas.

The present study for phytogenous substances has shown that the effect of the electron-beam distillation essentially differs from conventional pyrogenic distillation at comparable dynamics of heating. That electron-beam distillation transforms plant materials to organic liquid several times more productively than conventional dry distillation ${ }^{8}$.

The accelerated electron loses a small portion of energy (20 eV on the average), forming 2-5 nm spurs-the isolated zones of ionization and excitation ${ }^{10}$. The typical distance between spurs is hundreds of nanometers. The temperature of the kerogen degradation is more higher $270^{\circ} \mathrm{C}$ by the initiation of low-energy dehydration, dehydrogenations and decarboxylations of kerogen macromolecules. Water, carbondioxide and hydrogen are promptly removed from the heated sample. Recombination of the ionic and radical pairs in a spur results in the heat liberation and the temperature can reach to 1000 ${ }^{\circ} \mathrm{C}^{8}$. Thus, the sequence of the high temperature nanoreactors isolated from each other is promptly shaped along an electron trajectory. The high concentration of the intermediates (radicals

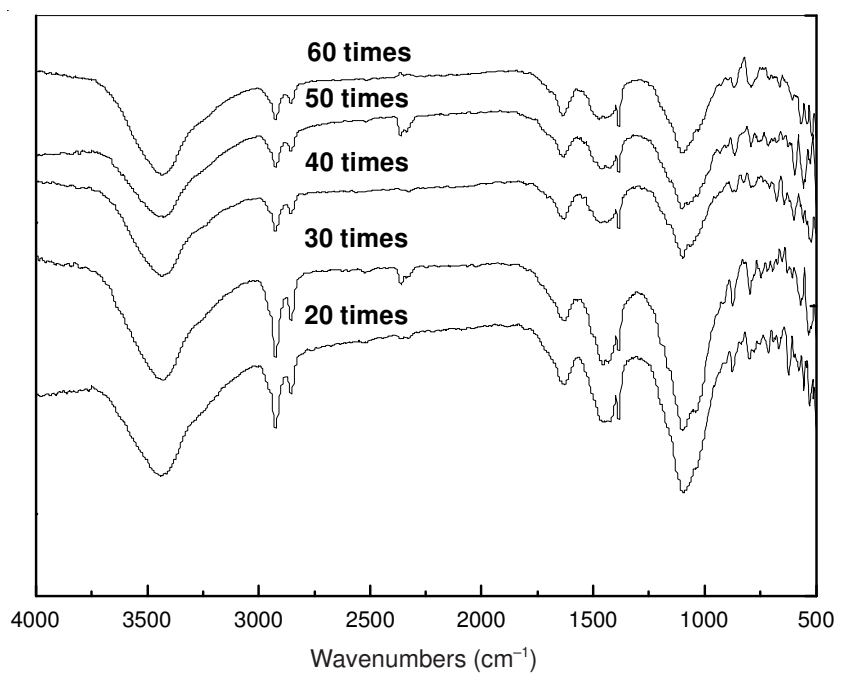

Fig. 4. FT-IR spectra of the residue products at difference number of the irradiation

and ions) formed exercises a significant influence on assortment of final products. Vacuum condition limits the secondary decomposition reactions, which as a result provides a high yield of hydrocarbon gas ${ }^{11}$. Colder bulk material promotes fast dissipation of excess energy from a spur, preventing the slower processes of low-energy destruction of kerogen macromolecules. Promptly formed unsaturated compounds (in particular, by disproportionation of radicals) capture the ${ }^{\circ} \mathrm{H}$ and ${ }^{\circ} \mathrm{OH}$ radicals, depressing a yield of $\mathrm{H}_{2} \mathrm{O}$ and $\mathrm{H}_{2}$ formation. Water can also participate in radiolytic processes, being the predecessor of alcohol and other oxychemicals ${ }^{10}$.

\section{Conclusion}

This work demonstrates the possibility of transforming oil shale into organic gas by electron-beam irradiation in vacuum system. A large amounts of water and charcoal can be produced by conventional pyrolysis method. In comparison, the electron-beam irradiation produces plenty of organic gas due to the restriction of the secondary decomposition and the formation of $\mathrm{H}_{2} \mathrm{O}$ and $\mathrm{H}_{2}$.

\section{ACKNOWLEDGEMENTS}

Funding for this work was provided by Chinese National Science Foundation (No. 50674024) and the Fundamental Research Funds for Central Universities (No. N090402009).

\section{REFERENCES}

1. J. Gersten, V. Fainberg, G. Hetsoni and Y. Shindler, Fuel, 79, 1679 (2000).

2. J.L. Qian and L. Yin, Oil Shale, Petroleum Industry Press, Beijing (2008).

3. Y.H. Liu, X.X. Xue and H. Yang, Adv. Sci. Lett., 4, 1838 (2011).

4. Y.H. Liu, X.X. Xue and Y. Li, Oil Shale, 28, 42 (2011).

5. T. Kaljuvee, J. Pelt and M. Radin, J. Therm. Anal. Calorim., 78, 399 (2004).

6. M.M.H. Senna, A.A. Abdel-Fattah and Y.K. Abdel-Monem, Nucl. Instrum. Methods Phys. Res. B, 266, 2599 (2008).

7. H.M. Abdel-Hamid, Solid-State Electron., 49, 1163 (2005).

8. A.V. Ponomarev, Radiat. Phys. Chem., 78, 345 (2009).

9. Y.H. Liu, X.X. Xue, Y. Li and J. Yazhou, J. Northeast Univ., 31, 1292 (2010).

10. R.J. Woods and A.K. Pikaev, Applied Radiation Chemistry: Radiation Processing, Wiley, New York (1994).

11. H. Pakdel, C. Roy and W. Kalkreuth, Fuel, 78, 365 (1999). 